OPEN ACCESS

Edited by:

Zsolt Illes,

University of Southern

Denmark, Denmark

Reviewed by:

Mastura Monif,

Monash University, Australia

Morten Blaabjerg,

University of Southern

Denmark, Denmark

*Correspondence:

Roland Dominic G. Jamora

rgjamora@up.edu.ph

orcid.org/0000-0001-5317-7369

Specialty section

This article was submitted to

Multiple Sclerosis and

Neuroimmunology,

a section of the journal

Frontiers in Neurology

Received: 02 October 2021

Accepted: 10 January 2022

Published: 07 February 2022

Citation:

Pagaling GT, Turalde CWR and Jamora RDG (2022) Autoimmune

Encephalitis in the Philippines: A Scoping Review on the Treatment Gaps, Challenges, and Current State of Care. Front. Neurol. 13:788309.

doi: 10.3389/fneur.2022.788309

\section{Autoimmune Encephalitis in the Philippines: A Scoping Review on the Treatment Gaps, Challenges, and Current State of Care}

\author{
Gerald T. Pagaling ${ }^{1}$, Christian Wilson R. Turalde ${ }^{1}$ and Roland Dominic G. Jamora ${ }^{1,2 *}$ \\ 'Department of Neurosciences, College of Medicine and Philippine General Hospital, University of the Philippines Manila, \\ Manila, Philippines, ${ }^{2}$ Institute for Neurosciences, St. Luke's Medical Center, Quezon City, Philippines
}

Objectives: We reviewed the current health service delivery for individuals with Autoimmune Encephalitis (AE) in the Philippines and to identify the gaps and challenges in its management.

Methodology: We conducted a scoping review of pertinent literature $A E$ in the Philippines using the Preferred Reporting Items for Systematic reviews and Meta-analysis (PRISMA) guidelines. We extracted data on epidemiology, legislation, health financing, information systems, pharmacotherapy, and healthcare services related to the management of $A E$ in the local setting.

Discussion: The epidemiology of $A E$ is still unknown. Out-of-pocket expenses contribute to most of the healthcare expenditure despite government-led programs to reduce the financial burden. The access to diagnostic examinations such as magnetic resonance imaging, electroencephalogram, and antibody testing is limited by the geographic distribution of the facilities and costs. The acute and long-term management of $\mathrm{AE}$ are cost-prohibitive and are not readily available. There are significant treatment gaps in the care of individuals with $\mathrm{AE}$ in the Philippines in terms of disease recognition, resource allocation, access to satisfactory diagnostic evaluation, and provision of prognosis-changing therapeutics. We proposed core strategies that can address these treatment gaps such as increasing awareness, improving access to health resources, adequate healthcare financing, and availability of support systems.

Keywords: autoimmune encephalitis, Philippines, management, treatment, challenges

\section{INTRODUCTION}

Autoimmune encephalitis (AE) is a non-infectious or para-infectious immune-mediated inflammatory disorder of the brain parenchyma, leptomeninges, and cerebral vessels commonly presenting with subacute onset alteration in mental status, memory deficits, or psychiatric symptoms accompanied by a variety of neurologic findings (1-4). Neurologic findings can be a focal central nervous system lesion, seizures, cerebrospinal fluid (CSF) pleocytosis, magnetic resonance imaging (MRI) features such as hyperintense T2-weighted fluid-attenuated inversion recovery signals in medial temporal lobes and multifocal inflammatory demyelinating areas of the gray and/or white matter $(1,2)$. 
Recent epidemiologic studies suggest that AE has an estimated prevalence rate of $13.7 / 100,000$ (3). The recent advances in the identification of antibodies and their associated syndromes can further uncover the real prevalence rate of $\mathrm{AE}$ as underreporting of this disorder is relatively common (2). However, the rapidly expanding knowledge on $\mathrm{AE}$ in both laboratory and clinical practice led to the heterogeneity of data regarding its clinical picture creating gaps in knowledge and practice. In particular, the diagnosis of autoimmune encephalitis necessitates diagnostic tests such as cranial magnetic resonance imaging (MRI), electroencephalogram (EEG), and cerebrospinal (CSF) studies that are not easily accessible $(1,2)$. Furthermore, the best available treatments of $\mathrm{AE}$ such as intravenous immunoglobulin (IVIG) administration, methylprednisolone pulse therapy (MPPT), plasma exchange (PLEX), and other immunosuppressive agents are also cost-prohibitive and are not readily available (5). The advances in the diagnosis and treatment of AE are usually available in high-income countries. The overall burden of $\mathrm{AE}$ is yet to be determined, however in general, the burden of neurologic diseases is high especially in lowto middle-income countries due to lack of funding allocated for health (6). The Philippines is categorized under the lowermiddle-income countries with a population of 110 million and is labeled as one of the countries with the highest disabilityadjusted life years per 100,000 population $(7,8)$. The burden of $\mathrm{AE}$ however is not yet established in the Philippines. To date, no comprehensive report has been made on the treatment gaps and challenges in AE care in the Philippines. We aimed to identify and evaluate the treatment gaps in the management of $\mathrm{AE}$ in the Philippines through systematic literature search and review of relevant Philippine websites.

\section{MATERIALS AND METHODS}

\section{Protocol}

Our study adhered to the Preferred Reporting Items for Systematic reviews and Meta-analysis (PRISMA) guidelines extension for the scoping review (9).

\section{Eligibility Criteria for Including Studies in the Scoping Review}

We considered published guidelines, meta-analyses, systematic reviews, review articles, randomized controlled trials, prospective/retrospective cohort studies, case series and reports, abstracts, conference proceedings, editorials, and textbooks with authors affiliated with an institution in the Philippines or with the study set in the Philippines. Human (both pediatric and adult population) and animal studies were included. Articles not in English or Filipino were excluded. No restriction in terms of the date of publication was implemented.

Abbreviations: AE, Autoimmune Encephalitis; CSF, Cerebrospinal Fluid; DOH, Department of Health; EEG, Electroencephalogram; FDG-PET, Fluorodeoxyglucose Positron Emission Tomography; IVIG, Intravenous Immunoglobulin; MPPT, Methylprednisolone Pulse Therapy; MRI, Magnetic Resonance Imaging; PhilHealth, Philippine Health Insurance Corporation; PLEX, Plasma Exchange.

\section{Information Sources}

We searched international (PubMed, Scopus, Clinicaltrials.gov, Ebscohost, Western Pacific Region Index Medicus, and Web of Science) and local (Health Research and Development Information Network) medical databases for relevant studies. We accessed pertinent and available literature via official websites and/or email correspondence with the following: international organizations, government and non-government agencies [Philippine Health Insurance Corporation (Philhealth), Department of Health (DOH), Philippine Statistics Authority], medical associations (Philippine Neurological Association, Autoimmune Encephalitis Clinicians Network, Philippine Academy of Rehabilitation Medicine), and private organizations (clinical laboratories and pharmaceutical companies).

\section{Search Selection of Sources}

We conducted a scoping review of literature from the earliest indexed record of the databases up to October 2021 using the following search term strategy that includes paraneoplastic and nonparaneoplastic cases: Autoimmune encephalitis OR autoimmune epilepsy OR Anti-Hu encephalitis OR AntiMa2 encephalitis OR AntiAMPAR encephalitis OR AntiLGI1 encephalitis OR AntiCASPR2 encephalitis OR AntiGAD65 encephalitis OR AntiGABAxA encephalitis OR AntiGABAxB encephalitis OR AntiDPPX encephalitis OR AntimGluR5 encephalitis OR AntiAK5 encephalitis OR AntixNeurexine3a encephalitis OR AntiPCA2 encephalitis OR AntiMAP1b encephalitis OR AntiNMDAR encephalitis OR AntiMOG encephalitis OR AntiCRMP5 encephalitis OR AntiCV2 encephalitis OR AntiRi encephalitis OR AntiKHL11 encephalitis OR AntiIgLON5 encephalitis OR AntiVGKC encephalitis OR AntiNIF encephalitis OR AntiGFAP encephalitis OR Glycine receptor encephalitis OR AntiAmphyphysin encephalitis OR seronegative autoimmune encephalitis AND Philippines. All titles and available abstracts were screened based on the eligibility criteria. GTP and CWT separately searched available literature. Duplicates were excluded. We retrieved the full-text eligible articles for data extraction.

\section{Data Charting Process and Items}

We extracted data on epidemiology, legislation, health financing, information systems, pharmacotherapy, and healthcare services related to the management of $\mathrm{AE}$ in the local setting. Details on authors, titles, and institutional affiliation were extracted from published studies. For the information on the specific cost of diagnostics and medications, communications were done with relevant laboratories and institutions.

\section{RESULTS}

\section{The Search of Studies}

The search yielded a total of 181 articles (Figure 1). We then screened 171 articles after the duplicates were removed. We excluded 161 articles that were not related to $\mathrm{AE}$ in the Philippines. Ten articles were assessed for eligibility, and we excluded four articles with no identified AE cases. Thus, a total of six data sources were included for synthesis. 

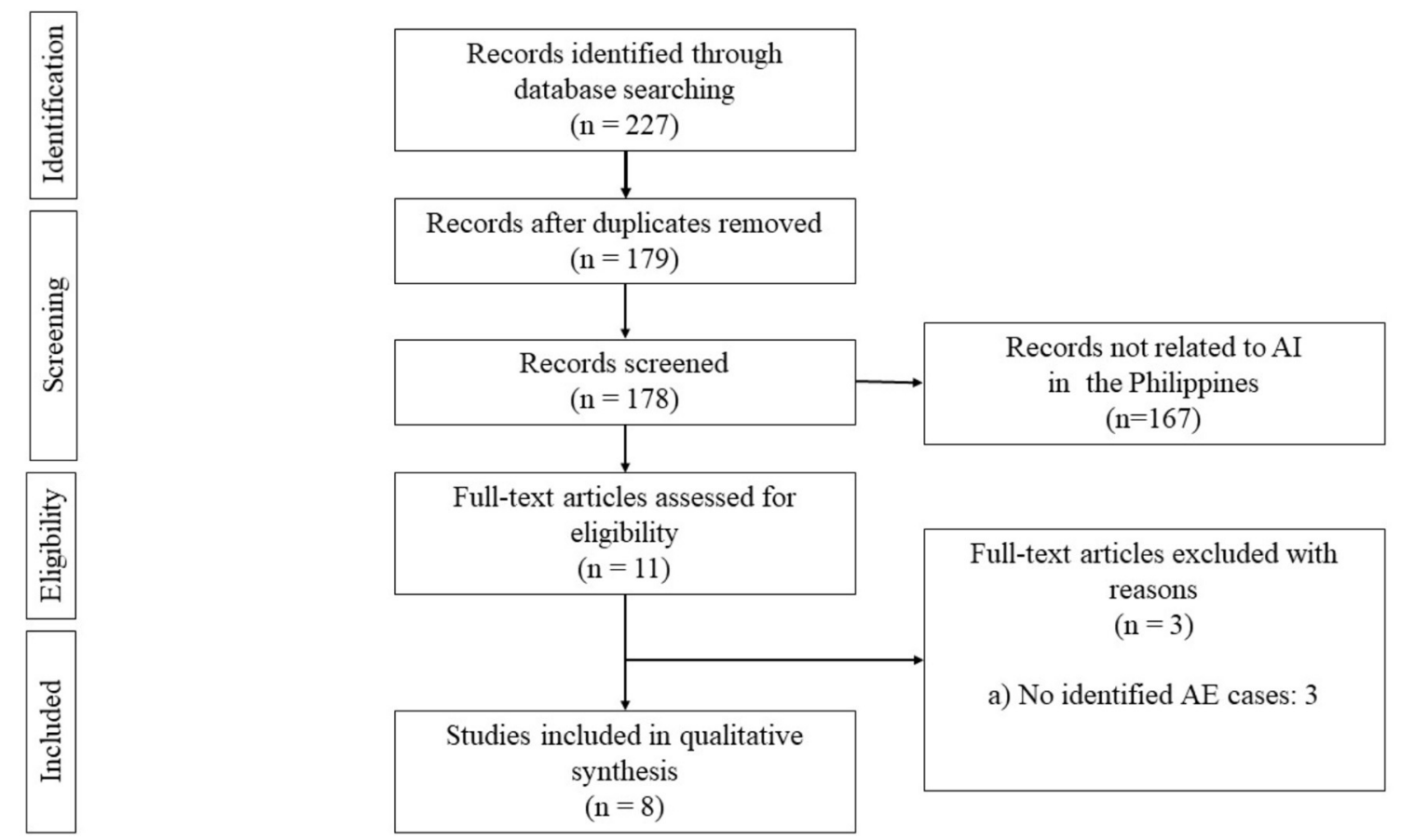

FIGURE 1 | Flow diagram adapted from PRISMA guidelines for scoping reviews.

\section{The National Acute Meningitis-Encephalitis Syndrome Surveillance and Case Registry}

In 2014, the Epidemiology Bureau mandated the establishment of a national surveillance system for acute encephalitis syndrome and meningitis. This encompasses all cases of bacterial meningitis, Japanese encephalitis, and encephalitides with pending work-up across all age groups in the country within nine sentinel hospitals (10). Last 2020 there were 1,437 identified cases with 77 recorded deaths (11). Last 2017, there were 778 suspected cases, 471 cases underwent testing and 57 cases tested positive for a specific etiologic agent. The identified cases were Japanese encephalitis virus, Streptococcus pneumoniae, Micrococcus, Neisseria meningitides, Haemophilus influenza, Dengue, Staphylococcus epidermidis, Streptococcus agalactiae, Pseudomonas, and Escherichia coli (12). It can be observed that only $60.5 \%$ of the labeled cases of meningitis-encephalitis in the Philippines underwent laboratory testing and only $7.33 \%$ cases have an identified etiology (12). The latest report did not further elaborate if the other identified cases have undergone additional testing such as work-up for autoimmune encephalitis (12). Although there were no publicly available individual data on the reported cases, the diagnoses of $92 \%$ of the cases remain to be identified. In the updated International Case Definition-10 (ICD-10) medical case rates in the Philippines, autoimmune encephalitis is not yet recognized as a diagnosis and only falls under the category "Encephalitis, myelitis, and encephalomyelitis, unspecified or Encephalitis, myelitis, and encephalomyelitis in other disease classified elsewhere" which limits proper reporting of identified cases (13).
Most of the hospitals in the Philippines still rely on printed medical records and only a small proportion of tertiary hospitals using electronic medical records. The law mandates that the electronic and non-electronic medical records are stored for only fifteen years (14). However, the retrieval of physical medical records for review can also prove to be cumbersome as proper record keeping is limited by the resources available in each institution such as quality of the papers, storage capacity of records division, and efficiency if archiving systems.

\section{Epidemiology of AE in the Philippines}

In a retrospective study done in 2020 that reviewed 18 cases (12 adults and six children) of patients with $\mathrm{AE}$ admitted to the Philippine General Hospital (PGH), the largest tertiary hospital providing neurologic care in the Philippines, the median age of onset was 13 years among pediatric cases and 32 years in the adult with a male-female ratio of 1:2.6 (15). Anti-NMDAR antibody $\mathrm{AE}$ was the most common type in adults (58.3\%) and children (100\%) and other documented syndromes had antibodies against alpha-amino-3-hydroxy-5-methyl-4-isoxazole propionic acid receptor (AMPAR), voltage-gated potassium channel complex (VGKC-complex), and multiple antibodies (NMDAR + AMPAR, NMDAR + VGKC) (15). The diagnosed cases with anti-VGKC antibodies still used this nomenclature since the identification of specific antibodies to the anti-VGKC namely leucine-rich glioma-inactivated (LGI1) and contactinassociated protein-like 2 (CASPR2) were not yet implemented. EEG was done in 17 of the patients where 16 had abnormalities with five adults presenting with status epilepticus (SE) (15). 


\begin{tabular}{|c|c|c|c|c|c|c|c|}
\hline Case & Age/sex & $\begin{array}{l}\text { Implicated } \\
\text { antibody/ies }\end{array}$ & $\begin{array}{l}\text { Clinical presentation and } \\
\text { associated neoplasm }\end{array}$ & $\begin{array}{l}\text { Electro-encephalo- } \\
\text { graphic findings }\end{array}$ & Treatment & Outcome & Reference \\
\hline 1 & $25 / F$ & $\begin{array}{l}\text { NMDAR Ab, } \\
\text { VGKC Ab }\end{array}$ & $\begin{array}{l}\text { Behavioral changes, seizures, } \\
\text { orofacial and limb dyskinesias, } \\
\text { associated with ovarian teratoma }\end{array}$ & $\begin{array}{l}\text { Electrographic seizures } \\
\text { arising from the right } \\
\text { fronto-temporal region }\end{array}$ & Surgery, MPPT, IVIG & Improved & Reyes et al. (17) \\
\hline 2 & 43/F & NMDAR Ab & $\begin{array}{l}\text { Behavioral changes, mutism, } \\
\text { seizures, neuroleptic malignant } \\
\text { syndrome }\end{array}$ & Not mentioned & Not mentioned & Not mentioned & Señga et al. (18) \\
\hline 3 & $46 / F$ & VGKC Ab & $\begin{array}{l}\text { Behavioral changes, seizures, } \\
\text { memory loss }\end{array}$ & $\begin{array}{l}\text { Intermittent slowing on } \\
\text { bilateral frontotemporal } \\
\text { regions, no epileptiform } \\
\text { discharges }\end{array}$ & MPPT & $\begin{array}{l}\text { Improved; able to perform } \\
\text { basic activities of daily living }\end{array}$ & Ocampo et al. (19) \\
\hline 4 & 36/F & $\begin{array}{l}\text { NMDAR Ab, } \\
\text { AMPAR Ab }\end{array}$ & $\begin{array}{l}\text { Behavioral changes, hallucinations, } \\
\text { orofacial dyskinesia, hyperekplexia, } \\
\text { ovarian teratoma }\end{array}$ & Slow activity & Surgery, MPPT, IVIG, RTX & Did not improve & Reyes et al. (15) \\
\hline 5 & $24 / F$ & NMDAR Ab & $\begin{array}{l}\text { Generalized seizures, hallucinations, } \\
\text { orofacial dyskinesias }\end{array}$ & Slow activity & MPPT, IVIG & Improved & \\
\hline 6 & $51 / \mathrm{M}$ & VGKC Ab & $\begin{array}{l}\text { Focal seizures, behavioral changes, } \\
\text { memory lapses, autonomic instability }\end{array}$ & $\begin{array}{l}\text { Slow activity, epileptic } \\
\text { activity }\end{array}$ & MPPT & Did not improve & \\
\hline 7 & $32 / F$ & NMDAR Ab & $\begin{array}{l}\text { Memory lapses, hallucinations, mania, } \\
\text { anhedonia, seizure, orofacial and limb } \\
\text { dyskinesias, ovarian teratoma }\end{array}$ & $\begin{array}{l}\text { Slow activity, epileptic } \\
\text { activity }\end{array}$ & Surgery, MPPT & Improved & \\
\hline 8 & $56 / \mathrm{M}$ & NMDAR Ab & $\begin{array}{l}\text { Speech disturbances, echolalia, } \\
\text { perseveration, anxiety, agitation, } \\
\text { hallucinations, aggression, memory } \\
\text { lapses }\end{array}$ & Slow activity & MPPT, IVIG & Improved & \\
\hline 9 & $44 / F$ & AMPAR Ab & $\begin{array}{l}\text { Memory lapses, hallucinations, } \\
\text { aggression, catatonia, mutism, status } \\
\text { epilepticus, orofacial and limb } \\
\text { dyskinesias }\end{array}$ & Not done & MPPT & Did not improve & \\
\hline 10 & 25/M & NMDAR Ab & $\begin{array}{l}\text { Speech disturbances, generalized } \\
\text { seizure, orofacial dyskinesias, } \\
\text { autonomic instability }\end{array}$ & Slow activity & MPPT, IVIG, RTX, CYC & Mortality & \\
\hline 11 & 29/M & NMDAR Ab & $\begin{array}{l}\text { Hallucinations, catatonia, anxiety, } \\
\text { speech disturbances, tremors }\end{array}$ & Slow activity & MPPT & Improved & \\
\hline 12 & $32 / F$ & VGKC Ab & $\begin{array}{l}\text { Seizure, status epilepticus, autonomic } \\
\text { instability }\end{array}$ & $\begin{array}{l}\text { Slow activity, epileptic } \\
\text { activity }\end{array}$ & MPPT, IVIG & Did not improve & \\
\hline 13 & 28/F & NMDAR Ab & $\begin{array}{l}\text { Seizures, orofacial dyskinesias, } \\
\text { autonomic instability, ovarian } \\
\text { teratoma }\end{array}$ & Slow activity & Surgery, MPPT, IVIG & Improved & \\
\hline 14 & 33/F & NMDAR Ab & $\begin{array}{l}\text { Hallucinations, paranoia, depressed } \\
\text { mood, tremors, autonomic instability }\end{array}$ & Slow activity & No treatment & Mortality & \\
\hline 15 & 10/F & NMDAR Ab & $\begin{array}{l}\text { Talkativeness, incoherent responses, } \\
\text { depressed mood, seizures, orofacial } \\
\text { dyskinesias, }\end{array}$ & Excessive beta activity & MPPT, IVIG, CYC & Improved & \\
\hline
\end{tabular}




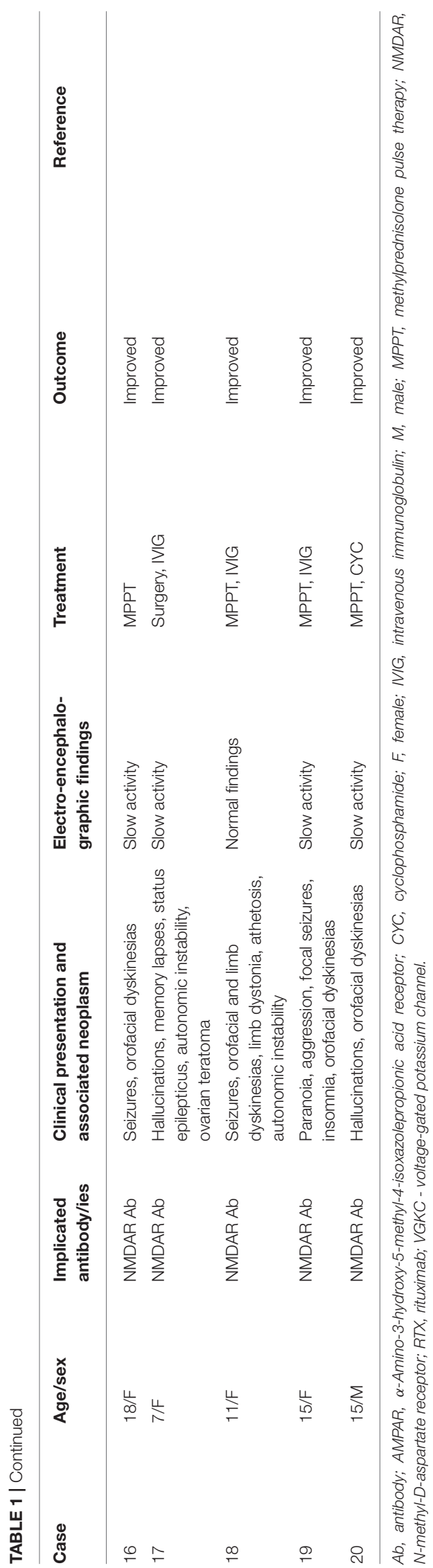

In terms of antiseizure treatment, 14 needed polytherapy and only three were on monotherapy (15). In terms of immunotherapy, 17 received first-line immunotherapy, nine had MMPT and IVIG, six had MPPT only, one had high dose MPPT and PLEX, and one had IVIG alone. For the second line immunotherapy, two had cyclophosphamide, one had rituximab, and one had rituximab and cyclophosphamide (15). There is still a deficiency in the updated and local epidemiological data on AE in the Philippines as there is still no existing national registry program for AE (16). Table 1 summarizes the clinical profile and outcomes of the identified AE cases in the Philippines from published data.

\section{Local Research in AE}

As of November 2021, there were only six indexed research outputs from the Philippines (Table 2): three case reports, two retrospective case series, and one abstract of a case report. Four studies were published in the last decade by authors affiliated with PGH.

\section{The Philippine Healthcare System}

The Philippines is an archipelago of 7,107 islands stretched across a land area of 298,170 square kilometers with a population of around 109 million as of 2020 (7, 22). The healthcare delivery system in the Philippines is divided into public and private sectors. The DOH handles national health policies and services while the local government units (LGU) are in charge of local service delivery and policy implementations (22). This devolution is dependent on the assumption that the LGUs are more abreast with the situation of their constituents and can promptly adapt to their dynamic needs (22). However, due to the topography of the Philippines, some rural areas are inevitably isolated rendering them disadvantaged in availing healthcare (22). Furthermore, this lack of access prevents the collection of population-specific data that will address the needs of the community $(22,23)$.

\section{Healthcare Cost and Coverage in the Philippines}

In 2019, the country's health care expenditure reached USD 15.9 billion (USD 1 = PHP 49.68 as of September 1, 2021), 47.9\% of this came from out-of-pocket payment while the government health care financing shoulders around $42.0 \%$ and the rest were covered from voluntary health care payments (24). However, in the past 20 years, the government's contribution to the health care expenditure has been decreasing from $37.34 \%$ in 2000 to only $29.29 \%$ in 2018 (25). Conversely, the proportion of outof-pocket expenditure in health has increased from $41.19 \%$ in 2000 to $52.85 \%$ in 2018 (25). The government healthcare financing is largely dependent on a tax-based budgeting system that funds government-led facilities throughout the country (22). Other government-led programs were developed to expand the coverage of health expenditure such as the PhilHealth and the Malasakit Center $(26,27)$. However, these only cover expenses upon hospital admission, and outpatient expenses from consultations, diagnostic examinations, and medications are usually paid on an out-of-pocket basis $(26,27)$. Moreover, 
TABLE 2 | Indexed research output on autoimmune encephalitis from the Philippines.

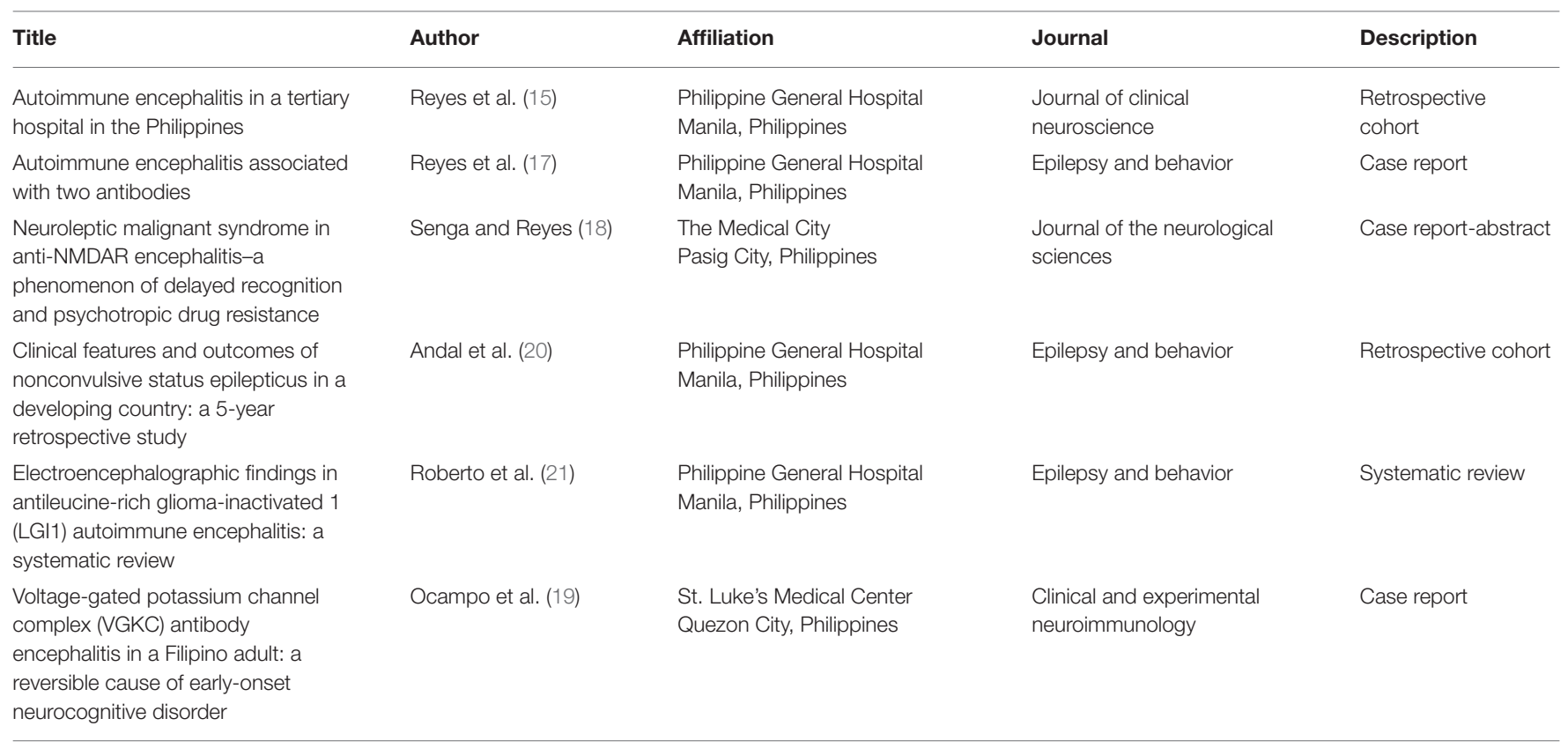

only $66 \%$ of the Filipino household population has any form of Philhealth and only $24 \%$ have other forms of public and private health insurances (28). Other measures to alleviate financial burden include the Magna Carta for Disabled Persons that entitles persons with disabilities to certain benefits including equal opportunity for employment, access to quality education, discounts for healthcare-related expenses (29). Autommine encephalitis is currently not listed in the list of medical cases covered by PhilHealth and can only fall under the category of other encephalitis not otherwise specified with a case rate of USD 432 (13). There are also non-government-led funding organizations that cater to patients with neurologic disease such as the Let's Save the Brain Foundation that can be tapped to provide support (diagnostic evaluation and treatment regimens) for patients with AE admitted at PGH (30).

\section{Specialty Training and Continuing Medical Education}

As of this writing, there are 508 active neurologist in the country, 421 adult neurologists, 83 pediatric neurologist, four adult and pediatric neurologists, one neurologist specializing in neuroimmunology, and two are members (pediatric neurologists) of the Autoimmune Encephalitis Clinicians Network (31). Approximately, one adult neurologist caters to 176,000 adult Filipinos or 0.57 adult neurologist to 100,000 adult population and one pediatric neurologist to 299,581 Filipino children or 0.33 pediatric neurologist to 100,000 pediatric population. This is below the World Health Organization recommendation of $1-5$ neurologists per 100,000 population (6). The adult neurology training in the country takes 3-4 years including training in internal medicine. The pediatric neurology fellowship takes 3 years. As of writing, there are only 11 accredited training institutions offering adult neurology residency; nine of which are in Manila, the capital (31). Subspecialty training in neuroimmunology is currently not available in the country. Due to the relatively new practice of neuroimmunology, there are still no programs aimed toward awareness and education of general practitioners and neurologists regarding autoimmune encephalitis.

\section{Challenges in Diagnosis}

The diagnosis of $\mathrm{AE}$ requires early extensive workup such as cranial MRI, EEG, CSF studies, fluorodeoxyglucose positron emission tomography (FDG-PET), and serum analysis (1, 2, 32).

As of 2016, there are only around $78 \mathrm{MRI}$ units (0.8 MRI units per online million population) in the country operated by public and private sectors, and the majority are located in Manila (22). Cranial MRI with contrast usually costs around USD 103-618 (33). There are only seven institutions that offer FDG-PET scans in the country and the price ranges from USD 604-1000. There is still no data available on the number of EEG units in the country and the cost is around USD 60-150.

The recommended CSF analyses to rule out other differential diagnoses include cell counts, protein, glucose, immunoglobulinG index, oligoclonal bands, viral panel, and culture studies $(1,2)$. CSF and serum antibody analysis usually confirm the inflammatory nature of encephalitis and the clinical recommendation is to send for the most comprehensive panel due to the significant overlap of clinical findings and antibodynegative cases $(1,2)$. The cost of the basic CSF analyses in the country ranges from USD 5-10. The only available AE antibody tests in the country are for antibodies against NMDA, $\mathrm{Hu}$, $\mathrm{Ma}$, and Ri which costs between USD 100-200 each, and the turnaround time is 3-4 weeks. CSF specimens are usually sent to diagnostic centers outside the country with a longer turnaround 
time. The comprehensive antibody tests are not available and are not covered in the benefit packages of Philhealth (13). Aside from the neurologic workup, it is also recommended to perform procedures to screen for cancer such as chest, abdominal, and pelvic CT scans, mammogram, and ultrasound since it is nearly impossible to predict if the encephalitis is paraneoplastic or non-paraneoplastic $(2,32)$.

In the local setting, immunologic procedures such as antibody tests are performed by licensed medical technologists under the supervision of board-certified pathologists (34). As of 2011, there were only 5,063 registered medical technologists in the country (medical technologist-to-population ratio of $1: 18,238$ ) (35). Despite the favorable healthcare professional-to-population ratio and the steady increase in the number of higher education institutions offering medical technology and medical laboratory science programs in the country (36), there is significant underutilization of medical technologists as majority of the laboratory facilities offer only minimal services such as acid-fast bacilli smears, urinalysis, and gram staining tests (37).

\section{Challenges in the Acute Treatment}

The 2016 AE clinical diagnostic criteria stress the need to start immunotherapy if AE is highly suspected and infectious causes are ruled out (1). Currently, there are only several retrospective studies that showed early and aggressive immunotherapy has led to better outcomes $(2,32,38)$. Anecdotal evidence includes the use of MPPT, IVIG, PLEX, and/or combination among the three as the first-line agents $(2,32,38)$. Second-line agents such as rituximab and cyclophosphamide are recommended if there are no clinical or radiological responses to first-line therapy after 2-4 weeks $(2,32,38)$. However, these treatment modalities are not readily available throughout the country, are cost-prohibitive, and are not included in the benefits package of Philhealth; hence financing is usually made as an out-of-pocket expense (13). The summary of the costs of treatment for AI in the Philippines is displayed in Table 3.

\section{Challenges in Long-Term Immunosuppression}

As per the recent treatment recommendations, acute therapy is followed by a gradual taper of immunosuppression $(5,32$, 38). Some cases require long-term immunosuppression such as cases related to neuronal surface antibodies and different $\mathrm{AE}$ phenotypes (5). However, since there are no formal guidelines or randomized-controlled trials to identify which patients or type of $\mathrm{AE}$ will require long-term immunosuppression, it will be based on the clinical decision of the neurologist to pursue continued immunosuppression or not, what type of immunosuppressive regimen, and for how long $(5,38)$. Some of the most popular immunosuppressants used aside from rituximab are azathioprine and mycophenolate mofetil $(5,38)$. The optimal duration of immunosuppressive therapy in $\mathrm{AE}$ is unknown, however, arbitrary recommendations suggest three years followed by reevaluation $(5,32)$.
TABLE 3 | Sample costing of treatment for autoimmune encephalitis in the Philippines (39).

\begin{tabular}{|c|c|c|}
\hline Drug name & Regimen & $\begin{array}{l}\text { Recommended price range } \\
\text { based on } 2020 \text { DPRI (USD)** }\end{array}$ \\
\hline
\end{tabular}

Available first-line immunosuppressive treatment

\begin{tabular}{|c|c|c|}
\hline $\begin{array}{l}\text { High dose pulse } \\
\text { corticosteroids }\end{array}$ & $\begin{array}{l}\text { IV } \\
\text { methylprednisolone } 1 \\
\text { gm OD x 5-7 days }\end{array}$ & $206.00-517.00$ \\
\hline $\begin{array}{l}\text { Plasmapheresis } \\
\text { (albumin) }\end{array}$ & $\begin{array}{l}\text { Every other day for } \\
5-10 \text { sessions }\end{array}$ & $1,509.66-6,622.40$ \\
\hline IV immunoglobulin* & $2 \mathrm{~g} / \mathrm{kg}$ for $3-5$ days & $4,931.40-5,072.46$ \\
\hline \multicolumn{3}{|c|}{ Available second-line immunosuppressive treatment } \\
\hline Rituximab & $\begin{array}{l}1 \mathrm{gm} \text { IV once a week } \\
\text { for } 4 \text { weeks }\end{array}$ & $1,074.76$ \\
\hline Cyclophosphamide* & $\begin{array}{l}600 \mathrm{mg} / \mathrm{m}^{2} \text { IV every } \\
4 \text { weeks }\end{array}$ & $2.51-3.98$ \\
\hline \multicolumn{3}{|c|}{ Other immunosuppressive regimens } \\
\hline $\begin{array}{l}\text { Azathioprine } 50 \\
\mathrm{mg} / \mathrm{tab}\end{array}$ & 50-300 mg per day & $562.10-1,693.60$ \\
\hline $\begin{array}{l}\text { Mycophenolate } \\
\text { mofetil } 100 \mathrm{mg} / \mathrm{tab}\end{array}$ & $500 \mathrm{mg} / \mathrm{tab}$ & $324.00-477.55$ \\
\hline
\end{tabular}

DPRI, Drug price reference index; IV, Intravenous; gm, gram; mg, milligram; $O D$, once a day. *Sample computation based on a $60 \mathrm{~kg}$ and $160 \mathrm{~cm}$ person, with body surface area of $1.63 / \mathrm{m}^{2}$. ${ }^{*}$ USD $1.00=$ PHP 49.68 as of September $1,2021$.

\section{Support Group}

There are currently no local support groups established in the Philippines for patients with AE. There are international networks for clinicians involved in the improvement of care for AE patients; however, only two Filipino neurologists are active members $(40,41)$.

\section{Rehabilitation Centers and Rehabilitation Medicine Specialists}

The majority of patients with $\mathrm{AE}$ have residual signs and symptoms that require physical therapy, neurorehabilitation, and neuropsychological support (5). Furthermore, many patients will require evaluation of their functional capacity before resumption to their previous role. While their value has not been fully investigated, the outcomes of rehabilitation from clinical experiences are promising (5). There are 452 rehabilitation centers and 316 rehabilitation medicine specialists in the country (42). However, the distribution of rehabilitation centers and rehabilitation medicine specialists is also skewed toward the urban areas (43).

\section{DISCUSSION}

Since its discovery, $\mathrm{AE}$ is a rapidly evolving neurologic disease. The rapid advances of $\mathrm{AE}$ research in the past 10 years led to its ever-changing practice in terms of diagnosis and management (1). This precipitous growth necessitates commensurate endeavors among clinicians to keep up with the new knowledge. However, healthcare information inequality is also evident as lower and middle countries lack the capability 
- Recognition of autoimmune encephalitis in the national health care programs

- Establishment of continuing medical education programs for autoimmune encephalitis

- Publication of local data and experiences
- Sufficient coverage for public and private health care insurance

- Inclusion of autoimmune encephalitis in health care packages

- Subsidy of drugs for acute and long-term treatment

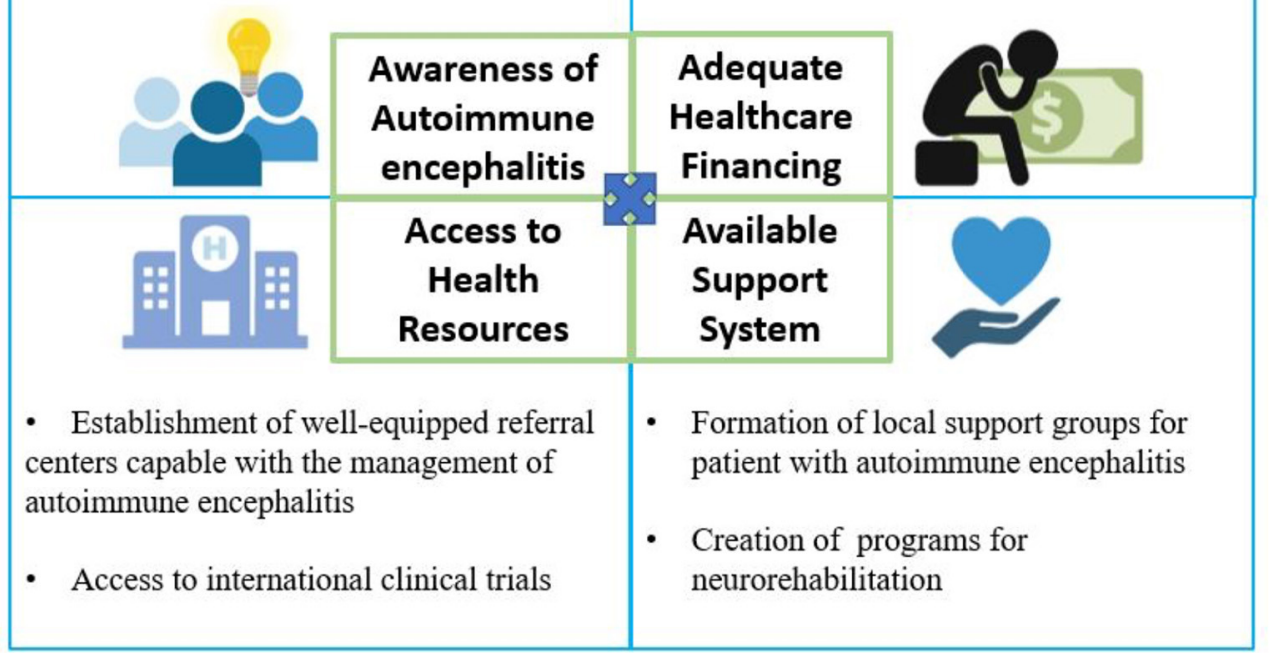

FIGURE 2 | Conceptual framework of the gaps in the management of autoimmune encephalitis in the Philippines.

to pursue research, the Philippines included. It is evident with the low number of studies and reports on the local experience on $\mathrm{AE}$ in the country that there is a need to pursue largescale studies encompassing multicenter protocols focusing on the epidemiology, clinical course, morbidity and mortality rates, quality of life, and life expectancies of persons diagnosed with $\mathrm{AE}$. The diagnosis of $\mathrm{AE}$ can be challenging since its clinical manifestations can be similar to other neuro-infectious and psychiatric disorders. Furthermore, objective evaluation requires the use of advanced facilities and diagnostic examinations to rule out other causes $(1,2)$. Due to the difficulty in establishing the diagnosis of $\mathrm{AE}$ and the lack of a robust registry system for patients with $\mathrm{AE}$, the Philippines lacks epidemiologic data on $\mathrm{AE}$ in which underreporting, and misdiagnosis is a major concern. This in turn restricts the opportunity to increase awareness of $\mathrm{AE}$ and limits the establishment of national health care programs targeted to this condition.

Our review found that the health services offered in the country are insufficient to meet the needs of individuals with AE. Access to a neurologist has significant implications since AE is a complex and evolving disease. Furthermore, the recommended diagnostic tests are unavailable to most of the population limiting the opportunity for prompt recognition and treatment. Most of the treatment regimens for $\mathrm{AE}$ are expensive, only available in tertiary hospitals, and are purchased as an out-of-pocket expense. Access to neurorehabilitation, which is essential to manage longterm complications and improve functional capacity, is also limited by its cost and the limited number of rehabilitation centers and physiatrists alike. The topography of the Philippines further highlights the inequality of care between its citizens since most hospitals and practitioners capable of managing $\mathrm{AE}$ are concentrated in urbanized areas. The country also lacks access to ongoing clinical trials in $\mathrm{AE}$ as large-scale clinical trials for $\mathrm{AE}$ are limited due to its vast number of subtypes (5). Health care policies still do not acknowledge the presence of $\mathrm{AE}$ as an emerging neurologic disease as evidence by its absence in the medical case rate of PhilHealth. The allocated case rate of USD 432 under the category of other encephalitis is barely enough to cover the diagnostic evaluation for the disease let alone the therapeutic regimes and possible long-term care (13). This inadequate coverage of government-led health care financing led the majority of Filipinos to spend from their own pockets. These findings are in line with the recent studies addressing the gaps in the management of different neurologic diseases (Parkinson's disease, primary brain tumor, multiple sclerosis, epilepsy, stroke) in the Philippines (23, 33, 42-44).

In general, the management of advanced neurologic diseases in the Philippines, $\mathrm{AE}$ included, presents with economic, governmental, and social challenges. Figure 2 summarizes these challenges together with the proposed recommendations to address these gaps. The awareness of $\mathrm{AE}$ is important for both societal and governmental programs to address these gaps. The next challenge is the access to comprehensive and timely diagnostic evaluation especially the access for the 
CSF and serum antibody testing. Problems with out-of-pocket expenditure can be addressed by promoting coverage from both public and private insurance institutions. Reducing the cost of cranial imaging is of utmost importance to facilitate access for initial evaluation. Institutional collaborations with accredited international laboratories coupled with adequate health financing present a viable option in addressing the lack of comprehensive CSF and serum antibody panel testing in the country. With the emerging evidence on the use of PLEX, IVIG, MPPT, rituximab, and cyclophosphamide, widespread availability of these drugs in government hospitals is recommended since they are already part of the national formulary. Lastly, establishing the practice of neuroimmunology in the Philippines can be promoted by supporting fellowship programs for neurologists outside the country.

\section{LIMITATIONS}

This review may not have identified all relevant studies in the published, unpublished, and unreported literature despite our efforts to be comprehensive as possible. The keywords use and the search algorithm may have missed other relevant terms. Our review only included an article published in English and may have missed other studies published in a different language. Reported cases of AE throughout the Philippines are also subject to bias from underrecognition, misdiagnoses, underreporting, and/or publication. Furthermore, the pair of reviewers used their judgment to determine whether the studies have sufficiently met our criteria and are subject to reviewer bias.

\section{REFERENCES}

1. Graus F, Titulaer MJ, Balu R, Benseler S, Bien CG, Cellucci T, et al. A clinical approach to diagnosis of autoimmune encephalitis. Lancet Neurol. (2016) 15:391-404. doi: 10.1016/S1474-4422(15)00401-9

2. Abboud H, Probasco JC, Irani S, Ances B, Benavides DR, Bradshaw M, et al. Autoimmune encephalitis: proposed best practice recommendations for diagnosis and acute management. J Neurol Neurosurg Psychiatry. (2021) 92:757-68. doi: 10.1136/jnnp-2020-325300

3. Dubey D, Pittock SJ, Kelly CR, McKeon A, Lopez-Chiriboga AS, Lennon VA, et al. Autoimmune encephalitis epidemiology and a comparison to infectious encephalitis. Ann Neurol. (2018) 83:166-77. doi: 10.1002/ana.25131

4. Flanagan EP, Caselli RJ. Autoimmune encephalopathy. Semin Neurol. (2011) 31:144-57. doi: 10.1055/s-0031-1277985

5. Abboud H, Probasco J, Irani SR, Ances B, Benavides DR, Bradshaw M, et al. Autoimmune encephalitis: proposed recommendations for symptomatic and long-term management. J Neurol Neurosurg Psychiatry. (2021) 92:897907. doi: 10.1136/jnnp-2020-325302

6. World Health Organization. Atlas: Country Resources for Neurological Disorders. 2nd edition. Geneva: WHO Press (2017). p. 97.

7. Philippine Statistics Authority. National Quickstat for 2021. (2021). Available online at: https://psa.gov.ph/statistics/quickstat/national-quickstat/all/ $\$ \wedge$ last $\$$ (accessed September 6, 2021).

8. World Health Organization. Neurological Disorders: Public Health Challenges. Geneva: WHO Press (2006). p. 232.

9. Page MJ, McKenzie JE, Bossuyt PM, Boutron I, Hoffmann TC, Mulrow $\mathrm{CD}$, et al. The PRISMA 2020 statement: an updated guideline for reporting systematic reviews. BMJ. (2021) 372:n71. doi: 10.1136/ bmj.n71

10. Department of Health. Acute Meningitis-Encephalitis Syndrome Surveillance Cases in the Philippines. (2015). Available online at: https://doh.gov.
To our knowledge, this is the first scoping review describing the gaps in the management of $\mathrm{AE}$ in the Philippines. Our study may have certain limitations in the access of articles especially on literature that is yet to be published and reports of local experiences of neurologists. The findings of our study promote awareness to patients, caregivers, clinicians, researchers, and legislators alike. The recognition of the treatment gaps in $\mathrm{AE}$ care in the Philippines strives to be the first step in promoting measures to improve health care delivery in the country.

\section{DATA AVAILABILITY STATEMENT}

The raw data supporting the conclusions of this article will be made available by the authors, without undue reservation.

\section{AUTHOR CONTRIBUTIONS}

All authors contributed to the study's conception and design. Material preparation, data collection, and analysis were performed by all of the authors. The first draft of the manuscript was written by GP and all authors commented on previous versions of the manuscript. All authors read and approved the final manuscript.

\section{ACKNOWLEDGMENTS}

We would like to acknowledge the Philippine Neurological Association for their assistance.

$\mathrm{ph} /$ sites/default/files/statistics/AMES\%20MW4.pdf (accessed November 20, 2021).

11. Department of Health. PIDSR Weekly Surveillance Report No. 26 2021. (2021). Available online at: https://doh.gov.ph/node/33237 (accessed November 20, 2021).

12. Department of Health. Acute Meningitis Encephalitis Syndrome Surveillance Report. (2017). Available online at: https://doh.gov.ph/sites/default/files/ statistics/2017\%20Acute\%20Meningitis\%20Encephalitis\%20Syndrome \%20Morbidity\%20Week\%201-22.pdf (accessed November 20, 2021).

13. Philippine Health Insurance Corporation. List of Medical Case Rates (Updated February 2017). (2017). Available online at: https://www.philhealth.gov. $\mathrm{ph} /$ circulars/2017/annexes/0019/AnnexA-MedicalCaseRates.pdf (accessed September 6, 2021).

14. Department of Health. Health Privacy Code Implementing the Joint Administrative Order No. 2006-0002 "Privacy Guidelines for the implementation of the Philippine Health Information Exchange". (2016). Available online at: http://ehealth.doh.gov.ph/index.php/93-health-privacycode/84-health-privacy-code (accessed September 6, 2021).

15. Reyes NGD, Espiritu AI, Agabao JF, Abejero JEE, Salonga-Quimpo RAM, et al. Autoimmune encephalitis in a tertiary hospital in the Philippines. J Clin Neurosci. (2021) 90:191-8. doi: 10.1016/j.jocn.2021.05.052

16. Department of Health. Disease Surveillance. (2021). Available online at: https://doh.gov.ph/statistics (accessed September 3, 2021).

17. Reyes NGD, Prado MB, Turalde CWR, Fernandez MLL. Autoimmune encephalitis associated with two antibodies. Epilepsy Behav Case Reports. (2018) 10:44-6. doi: 10.1016/j.ebcr.2018.04.001

18. Señga MM, Reyes JPB. Neuroleptic malignant syndrome in anti-NMDAR encephalitis-a phenomenon of delayed recognition and psychotropic drug resistance. J Neurol Sci. (2019) 405:152-3. doi: 10.1016/j.jns.2019.10.1066

19. Ocampo FF, Saniel EG, Martinez MSC. Voltage-gated potassium channel complex (VGKC) antibody encephalitis in a Filipino adult: a reversible 
cause of early-onset neurocognitive disorder. Clin Exp Neuroimmunol. (2021) 12:72-5. doi: 10.1111/cen3.12609

20. Andal VMD, Espiritu AI, Geronimo MAG, Salonga-Quimpo RAM, Gosiengfiao KTP, Fernandez MLL. Clinical features and outcomes of nonconvulsive status epilepticus in a developing country: a 5-year retrospective study. Epilepsy Behav. (2020) 113:107547. doi: 10.1016/j.yebeh.2020.107547

21. Roberto KT, Espiritu AI, Fernandez MLL, Gutierrez JC. Electroencephalographic findings in antileucine-rich glioma-inactivated 1 (LGI1) autoimmune encephalitis: a systematic review. Epilepsy Behav. (2020) 112:107462. doi: 10.1016/j.yebeh.2020.107462

22. Dayrit MM, Lagrada LP, Picazo OF, Pons MC, Villaverde MC. The Philippines Health System Review. In: Patcharranarumol W, Tangcharoensathien V, editors. Health Systems in Transition. Geneva: WHO Press (2018). p. 316.

23. Jamora RDG, Miyasaki JM. Treatment gaps in Parkinson's disease care in the Philippines. Neurodegener Dis Manag. (2017) 7:245-51. doi: 10.2217/nmt-2017-0014

24. Philippine Statistics Authority. Philippine National Health Accounts. (2019). Available online at: https://psa.gov.ph/pnha-press-release/node/163258 (accessed August 29, 2021).

25. World Health Organization. Global Health Expenditure Database. (2021). Available online at: https://apps.who.int/nha/database/country_profile/ Index/en (accessed September 3, 2021).

26. Official Gazette. Republic Act No. 9241: An act amending the Republic Act No. 7875, otherwise known as "an act instituting a national health insurance program for all Filipinos and establishing the Philippine Health Insurance corporation for the purpose". (2004). Available online at: https://www. officialgazette.gov.ph/2004/02/10/republic-act-no-9241/ (accessed August 29, 2021).

27. Official Gazette. Republic Act No. 11463: An act establishing malasakit centers in all department of health hospitals in the country and in the Philippine General Hospital (PGH), providing funds therefor and for other purposes. (2019). Available online at: https://www.officialgazette.gov.ph/2019/12/03/ republic-act-no-11463/ (accessed August 29, 2019).

28. Philippine Statistics Authority. Philippines National Demographic and Health Survey: Key Indicators. (2017). Available online at: https://psa.gov.ph/sites/ default/files/Philippines\%20NDHS\%20KIR.pdf (accessed August 29, 2021).

29. Official Gazette. Republic Act No. 9442: An act amending republic act no, 7277, otherwise known as the "Magna Carta for disabled persons, and for other purposes". (2007). Available online at: https://www.officialgazette.gov. ph/2007/04/30/republic-act-no-9442/ (accessed August 29, 2021).

30. Let's Save the Brain Foundation. (n.d.). Vision \& Mission. Available online at: https://letssavethebrain.org/vision-mission/ (accessed September 4, 2021).

31. Philippine Neurological Association. (2020). PNA Fellows. Available online at: https://www.philippineneurologicalassociation.com/pan-fellows (accessed September 3, 2021).

32. López-Chiriboga AS, Flanagan EP. Diagnostic and therapeutic approach to autoimmune neurologic disorders. Semin Neurol. (2018) 38:392402. doi: 10.1055/s-0038-1660819

33. Mondia MWL, Espiritu AI, Batara JMF, Jamora RDG. Neuro-oncology in the Philippines: a scoping review on the state of medical practice, deterrents to care and therapeutic gaps. Ecancermedicalscience. (2021) 15:1238. doi: 10.3332/ecancer.2021.1238

34. Philippine House of Representatives (2011). Medical Technology Act of 2011. Available online at: https://legacy.senate.gov.ph/lis/bill_res.aspx?congress= $15 \& \mathrm{q}=\mathrm{SBN}-2722$ (accessed November 3,2021$)$.
35. World Health Organization. Human Resources for Health Profiles: Philippines 2011 (2013). Available online at: https://iris.wpro.who.int/ bitstream/handle/10665.1/7869/9789290616245_eng.pdf. (accessed August 23, 2021).

36. United States Agency for International Develeopment. Human Resources for Health Masterplan: Situational Analysis. (2019). Available online at: https:// hrh2030program.org/wp-content/uploads/2020/08/x12.3_HRH2030PH_ HRHMP_Situation-Analysis.pdf (accessed August 23, 2021).

37. United States Agency for International Development. Determining Staffing Levels for Primary Care Services using Workload Indicator of Staffing Need in Selected Regions of the Philippines. (2019). Available online at: https:// hrh2030program.org/wp-content/uploads/2020/08/2.1_HRH2030PH_ WISN-SDN-Phase-1-Report.pdf (accessed August 23, 2021).

38. Shin YW, Lee ST, Park KI, Jung KH, Jung KY, Lee SK, et al. Treatment strategies for autoimmune encephalitis. Ther Adv Neurol Disord. (2018) 11:1756285617722347. doi: 10.1177/175628561772 2347

39. Department of Health. The Philippine Drug Price Reference Index. (2020). Available online at: https://dpri.doh.gov.ph/index.php?page=downloads (accessed August 23, 2021).

40. Autoimmune Encephalitis Alliance. (n.d.). Join the Clinicians Network. Available online at: https://aealliance.org/find-a-doctor/join/\#:|sim:text=The $\% 20$ Autoimmune $\% 20$ Encephalitis\%20Alliance $\% 20$ offers, further\%20enhance \%20care\%20and\%20research (accessed September 2, 2021).

41. International Autoimmune Encephalitis Society. (n.d.). Asia: Philippines. Available online at: https://autoimmune-encephalitis.org/asiadocsphillipines/ (accessed September 5, 2021).

42. Collantes ME, Zuñiga YH, Granada CN, Uezono DR, de Castillo LC, Enriquez CA, et al. Current state of stroke care in the Philippines. Front Neurol. (2021) 12:665086. doi: 10.3389/fneur.2021.665086

43. Ignacio KHD, Espiritu AI, Jamora RDG. The current status and challenges in multiple sclerosis management in the Philippines. Mult Scler Relat Disord. (2020) 46:102510. doi: 10.1016/j.msard.2020.1 02510

44. Moalong KMC, Espiritu AI, Fernandez MLL, Jamora RDG. Treatment gaps and challenges in epilepsy care in the Philippines. Epilepsy Behav. (2021) 115:107491. doi: 10.1016/j.yebeh.2020.107491

Conflict of Interest: The authors declare that the research was conducted in the absence of any commercial or financial relationships that could be construed as a potential conflict of interest.

Publisher's Note: All claims expressed in this article are solely those of the authors and do not necessarily represent those of their affiliated organizations, or those of the publisher, the editors and the reviewers. Any product that may be evaluated in this article, or claim that may be made by its manufacturer, is not guaranteed or endorsed by the publisher.

Copyright (C) 2022 Pagaling, Turalde and Jamora. This is an open-access article distributed under the terms of the Creative Commons Attribution License (CC BY). The use, distribution or reproduction in other forums is permitted, provided the original author(s) and the copyright owner(s) are credited and that the original publication in this journal is cited, in accordance with accepted academic practice. No use, distribution or reproduction is permitted which does not comply with these terms. 